\title{
HYPOTENSIVE EFFECT INDUCED BY STRENGTH TRAINING USING THE DELORME AND OXFORD METHODS IN TRAINED MEN
}

\author{
JAIME DELLA CORTE', GABRIEL ANDRADE PAZ1', JULIANA BRANDÃO PINTO DE CASTRO², \\ HUMBERTO MIRANDA ${ }^{1}$ \\ ${ }^{1}$ Federal University of Rio de Janeiro, School of Physical Education and Sports, \\ Postgraduate Programme in Strength Training, Rio de Janeiro, Brazil \\ 2Rio de Janeiro State University, Institute of Physical Education and Sports, \\ Postgraduate Programme in Exercise and Sport Sciences, Rio de Janeiro, Brazil
}

\author{
Mailing address: Juliana Brandão Pinto de Castro, Rio de Janeiro State University, Institute of Physical Education \\ and Sports, 524 São Francisco Xavier Street, 20550-900 Maracanã, Rio de Janeiro, tel.: +55 2123340107 , \\ fax: +55 21 23340573, e-mail: julianabrandaoflp@hotmail.com
}

\begin{abstract}
Introduction. The aim of the study was to investigate the hypotensive responses in normotensive trained individuals after strength training (ST) performed using two training methods: DeLorme and Oxford. Material and methods. Fifteen normotensive trained men (age: $25.1 \pm 3.2$ years; height: $1.78 \pm 0.01 \mathrm{~m}$; BMI: $24.78 \pm 1.4 \mathrm{~kg} / \mathrm{m}^{2}$ ) were examined alternately in crossover with an interval of 72 hours between the DeLorme and Oxford methods. Firstly, 10 repetition maximum (RM) loads were obtained. DeLorme (50\%, 70\%, and 90\%) and Oxford (90\%, 70\%, and 50\%) consisted in the manipulation of 10RM loads so that the subjects performed three sets until failure in the Smith Machine (SM) and the Leg Press $45^{\circ}$ (LP). Blood pressure was recorded at rest, post-exercise, and until 60 min post-session at 10-min intervals. Results. Both the DeLorme and Oxford methods showed significant intra-protocol reduction in systolic blood pressure (SBP) at 40, 50, and 60 min time points compared to the rest value $(F=21.848 ; p=0.0001)$. Similar results were noted for diastolic blood pressure $(\mathrm{DBP})$ between rest value and the 60 min time point $(\mathrm{F}=46.113 ; \mathrm{p}=0.0001)$. Conclusions. The DeLorme and Oxford resistance training methods provided similar hemodynamic responses and similar hypotensive effects. Therefore, these methods can be used as alternatives to manipulate training intensity-volume ratio intra-session with low hemodynamic stress.
\end{abstract}

Key words: blood pressure, strength training, hypertension, hypotension, male

\section{Introduction}

Systemic arterial hypertension (SAH) is a multifactorial clinical condition characterised by high and sustained levels of blood pressure (BP). SAH is often associated with functional and/or structural changes in specific organs (heart, brain, kidneys, and blood vessels) and metabolic disorders, which lead to increased risk of fatal and nonfatal cardiovascular events [1, 2]. $\mathrm{SAH}$ is still a highly prevalent disease also considered a public health problem worldwide. In many cases, it has an asymptomatic course, being difficult to control and leading to negligence in the diagnosis and treatment [3].

To prevent and treat cardiovascular disease, its risk factors, and other chronic diseases, the regular practice of physical activity is recommended [4]. Strength training (ST) and the manipulation of methodological prescription variables (i.e., order of exercises, rest interval between sets and exercises, and number of sets and repetitions) can induce different physiological responses, having a direct impact on the behaviour of BP post training session. Thus, ST has been suggested as a non-pharmacological alternative for the prevention and treatment of SAH [5-7].

A single session of ST can provide important benefits to the cardiovascular system with a reduction in BP levels during the post-exercise period compared to those observed in the preexercise rest [8-10]. This effect is known as post-exercise hypotension (PEH) [11], which can play an important role in control- ling SAH and cardiovascular risk [12]. There are findings that chronic BP reductions, due to the continued participation in ST programmes, result largely from the sum of acute hypotensive effects of training sessions [13].

The magnitude of the hypotensive effect may be related to the volume of training, load intensity, and the muscle groups exercised [14]. Rezk et al. [15] observed a hypotensive response to systolic blood pressure (SBP) in normotensive people after low intensity ST (40\% of 1 repetition maximum - 1RM) and after high intensity ST ( $80 \%$ of $1 \mathrm{RM})$, but the reduction in diastolic blood pressure (DBP) was only observed in low-intensity exercise. Prista et al. [16] found that, in Mozambique men, a single ST session with eight exercises on different muscle groups (1 set of 10 to 15 repetitions of 30 to $60 \%$ of $1 R M$ ) was not able to decrease BP under clinical conditions after training but could reduce it during sleep. Furthermore, Bentes et al. [17] compared the responses of the hypotensive effect of ST in apparently healthy women between different intensities (60\% and $80 \%$ of IRM) in various exercise orders. They reported significant reductions in SBP and DBP after four ST sessions with manipulation of intensity and exercise sequence.

However, the results are still contradictory when it comes to the methods applied in ST and the magnitude and/or duration of the hypotensive responses, as well as the physiological mechanisms associated with PEH [18]. Considering the lack of results on the PEH induced by the DeLorme and Oxford methods, it is 
relevant to investigate the hypotensive effect of such protocols. DeLorme and Oxford are training methods that involve exercises of increasing and decreasing intensity, respectively. Nevertheless, few researchers have controlled the hemodynamic variables during the ST at different intensities; this justifies the need to investigate the BP responses in post-exercise according to the responses during the training sessions, which would make it possible to guide the interventions of health professionals in relation to the risk-benefit of the effort [19].

Therefore, the purpose of the current study was to investigate the hypotensive responses of SBP, DBP, and mean blood pressure (MBP) in normotensive trained individuals after ST implemented using two training methods: DeLorme and Oxford.

\section{Material and methods}

\section{Participants}

Fifteen apparently healthy men (age: $25.1 \pm 3.2$ years; height: $1.78 \pm 0.01 \mathrm{~m}$; BMI: $24.78 \pm 1.4 \mathrm{~kg} / \mathrm{m}^{2}$ ) participated in this study. To be included in the study, a subject had to: a) be a normotensive free of the use of beta-blockers, angiotensin converting enzyme inhibitors, diuretics, corticosteroids, and $\mathrm{Ca}^{2+}$ channel blockers; b) have practised ST for at least one year, with a weekly frequency of more than four days and session time greater than 60 minutes; and c) be negative in the Physical Activity Readiness Questionnaire (PAR-Q) [20]. Individuals with degenerative or metabolic diseases, with injury or musculoskeletal limitations that precluded the realisation of the programmed exercises, with any cardiovascular disorders, or using ergogenic aids were excluded from the study.

This project was submitted and approved by the institution ethics committee. Therefore, this study met the standards for conducting research on human beings in accordance with the Declarations of Helsinki and of the National Health Council of Brazil. All participants signed an informed consent form.

\section{Procedures}

Each volunteer performed four visits on non-consecutive days. The visits always took place at the same times and with an interval of 48 to 72 hours. In the first visit, subjects got detailed explanations on all data collection procedures and study interventions, answered PAR-Q items, signed the consent form, and were submitted to anthropometric measurements and tests of 10 maximum repetitions (10RM). Forty-eight hours after the IORM tests, the subjects visited the second time and submitted to retesting of 10RM. After 72 hours, between the third and fourth visit, in crossover, participants alternately performed the training session, with hemodynamic responses measured before and after ST (Fig. 1).

\section{Anthropometric measurements}

To characterise the sample, height was determined with the use of a Sanny ${ }^{\circledR}$ stadiometer (ES2020 model, Brazil), with a length of $2.10 \mathrm{~m}$ and accuracy of $0.001 \mathrm{~m}$. The measurement of body composition (total body mass - TBM, skeletal muscle mass - SMM, fat mass - FM, and fat percentage - \%F) was assessed through direct multifrequency bioimpedance (BIA) with eight-point tactile electrodes using InBody ${ }^{\circledR}$ (230 Biospace model, South Korea) [21], with a limit of $250 \mathrm{~kg}$ and an accuracy of $100 \mathrm{~g}$. Fat-free mass (FFM) was calculated as the difference between TBM and FM. BMI was calculated using the ratio of TBM $(\mathrm{kg})$ and height squared $\left(\mathrm{m}^{2}\right)$. Anthropometric measure- ments followed the specific protocols suggested in the International Standards for Anthropometric Assessment (ISAK) [22].

In the measurements with the BIA, all subjects received the following recommendations [23]: 1) do not use diuretics in the last seven days before the measurement; 2) remain fasting for at least four hours; 3 ) do not drink alcohol in the last 48 hours; 4) refrain from intense physical exercise in the last 24 hours; and 5) urinate at least 30 minutes before the measurement. At the time of measurement, the subjects wore light clothes, were barefoot, and had no metal adornments.

\section{Ten-repetition maximum (10RM) test}

To check the training load and exercise prescription criteria, we applied the 10RM test, following the recommendations of Baechle and Earle [24]. The equipment used included the Smith Machine Hammer Strength $@$ (HSSM Life Fitness model, USA) and the Leg Press $45^{\circ}$ Technogym $($ C (Pure Strength MG5000 model, Italy). In order to reduce the error margin in the tests, the following strategies were adopted [25]: 1) standardised instructions were given before exercise, so that the subjects were aware of the whole routine of data collection; 2) instructions were also provided regarding the technique of performing the exercise; 3 ) the appraiser was attentive to the position of the subjects during the tests, since small variations in the positioning of the joints involved in the movement could influence the work of the muscles, leading to misinterpretations of the scores obtained; 4) verbal incentives were used in order to maintain a high motivation level; 5) the additional weights used in the study had been calibrated for digital accuracy with the electronic scale Toledo ${ }^{\circledR}$ (2098 PP model, Brazil).

Tests of 10RM were performed in a single day, following the order of the equipment described above. The warm-up consisted of 15 repetitions with $50 \%$ of the estimated training load of each participant. Three minutes after the warm-up, the subject

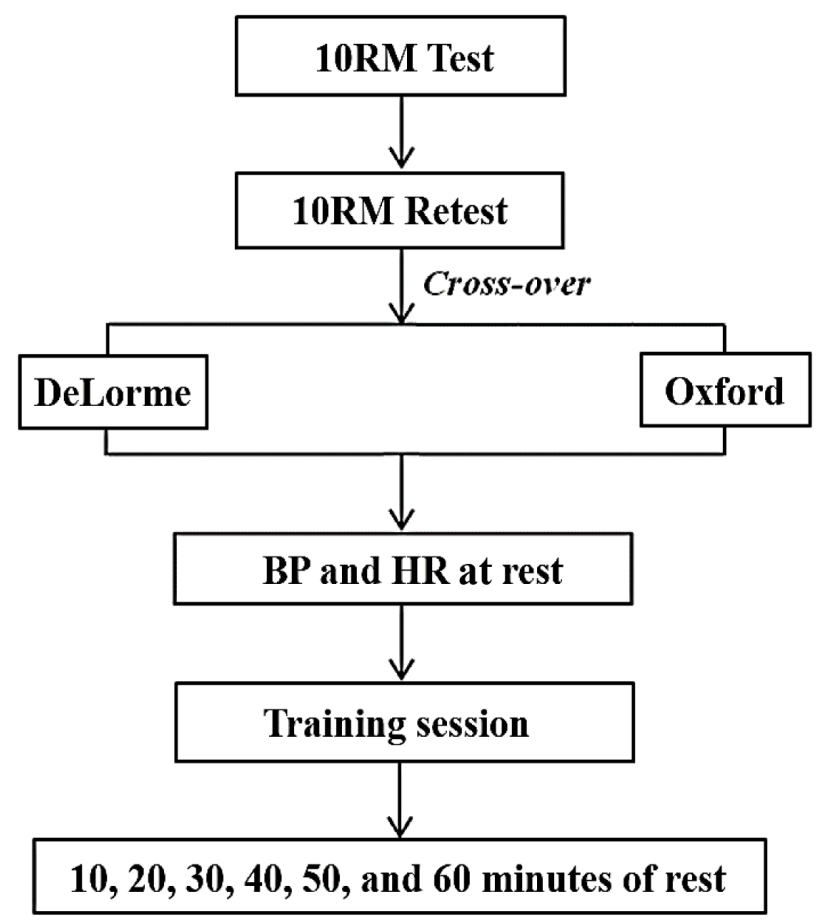

Figure 1. Schematic model of the research; BP = blood pressure measurement; $\mathrm{HR}$ = heart rate measurement 
attempted the first of the three movement executions. The initial load was estimated according to the load commonly used by the volunteer in their training sessions.

For a better description of the movement, we established the following execution steps: starting position, concentric phase, and eccentric phase. For the Smith Machine (SM), the steps were as follows: a) starting position: individual standing with hips and knees in full extension, legs parallel with a small lateral distance between 30 and $40 \mathrm{~cm}$, secure training bar, supported on the line of the upper trapezius, elbows flexed and aligned with shoulders in abduction; b) concentric phase: from the initial phase, performance of a bilateral squat with knee flexion of at least $90^{\circ}$; c) eccentric phase: return to the starting position. For the Leg Press $45^{\circ}$ (LP), the steps were the following: a) starting position: volunteer with his head positioned in the Frankfurt plane, sitting with his back fully supported at a $45^{\circ}$ angle, arms along the body holding the handlebar, legs parallel with lateral distance and knees flexed $\left(80^{\circ}\right.$ between the leg and thigh); b) concentric phase: from the initial position, performance of a full extension of knees and hips; c) eccentric phase: return to the starting position.

The tests were stopped when the subject was unable to perform the complete movement, which occurred voluntarily at concentric failure in 10RM [24]. The speed of movement execution was two seconds for the concentric phase and two seconds for the eccentric phase. The validation took place under the following criteria: a) no interval was allowed between the concentric and eccentric phases, and b) the repetitions that did not meet the required technical standards were not counted.

In order to minimise premature fatigue, the recovery between attempts during the 10RM test was fixed at five minutes [26]. If the overhead for training was not obtained after three attempts, the test was to be cancelled and held on a nonconsecutive day after the previous attempt. After the three attempts at 10RM using a particular piece of equipment, we gave recovery intervals of not less than 10 minutes before proceeding to the 10RM test in the next strength exercise [27]. After obtaining the loads in the 10RM tests, in order to assure the reproducibility of the overloads [28], subjects rested for at least 48 hours and took a retest following the same test procedures. The established load for 10RM was the overhead achieved on both days with a difference between them of less than $5 \%$. However, if this difference exceeded the percentage stipulated, a new test and retest were required.

\section{Training sessions}

The participants in this study were instructed not to perform physical exercise of any kind and not to ingest stimulants in the 24 hours before the data collection and the intervention. All tests, retests, and training sessions were conducted at times similar to those of the training sessions in a room with a controlled temperature between 18 and 22 Celsius $\left({ }^{\circ} \mathrm{C}\right)$.

For the analysis of the hypotensive effect, through the crossover experiment, subjects were tested alternately on two non-consecutive days, with a minimum interval of 72 hours between training sessions. In the DeLorme Protocol, participants underwent ST with increasing loads [29], with specific warm-up [30] in the SM, which consisted of two sets of 15 repetitions with a one-minute interval, using a load of $40 \%$ of 10RM obtained between test and retest. Three minutes after the warm-up, subjects did three series of DeLorme Protocols. In this method, the load gradually increases immediately after the number of programmed repetitions is reached or after voluntary concentric failure, and this process is progressively repeated with no break during one series. DeLorme starts with a load of 50\% of 10RM, interlocked, without rest, with successive loads of 70\% and 90\% of 10RM. At the end of the third series in the SM, three minutes after the above procedures, the participants began the three series in the LP.

In the Oxford Protocol, volunteers underwent ST with decreasing loads [29], with specific warm-up also in the SM. The warm-up consisted of two sets of 15 repetitions at one-minute intervals, using $40 \%$ of 10RM obtained between test and retest. Three minutes after the warm-up, volunteers did three series of Oxford Protocols. In this method, the load gradually decreases immediately after the number of programmed repetitions is reached or after voluntary concentric failure, and this process is progressively repeated, with no break during one series. Oxford starts with $90 \%$ of $10 \mathrm{RM}$, interlocked, without rest, with successive loads of $70 \%$ and $50 \%$ of $10 \mathrm{RM}$. At the end of the third series in the SM, three minutes after the above procedures, the volunteers began the three series of Oxford.

During the execution of the series with the DeLorme and Oxford Protocols, individuals were encouraged to exhale in the concentric phase and inhale on the eccentric phase of the movement, thus avoiding the Valsalva manoeuvre. The speed of movement execution was the same in tests and retests. The intervals between sets were three minutes long. At the end of each training session, participants indicated the perceived exertion (PE) according to the OMNI scale [31]. The subjects in the third series of the ST were placed on LP equipment already using a clamp blood pressure device, positioned on the left arm about $2 \mathrm{~cm}$ above the antecubital fossa.

\section{Hemodynamic measures}

All records of $\mathrm{BP}$ and $\mathrm{HR}$ were obtained using the digital pressure device Microlife ${ }^{\circledR}$ (BP 3BTO-A model, Switzerland) [32], approved and certified according to the protocols of the British Hypertension Society (BHS), the Association for the Advancement of Medical Instrumentation (AAMI), the American Heart Association (AHA), the Food and Drug Administration (FDA), the Kidney and Hypertension Hospital, Federal University of São Paulo (IPEPENHI-UNIFESP), the Brazilian National Institute of Metrology, Quality and Technology (INMETRO), and the Brazilian National Sanitary Surveillance Agency (ANVISA).

Hemodynamic measures under review in the DeLorme and Oxford sessions were held at three respective times: rest (ten minutes in an empty and quiet room with controlled temperature between 18 and $22^{\circ} \mathrm{C}$ and with the body and hands in the supine position), post-exercise (in the LP, sitting position, uncrossed feet and hands in the supine position, following the last series of the training session of a particular method), and 60 minutes rest $(10,20,30,40,50$, and 60 minutes after the training session, at the same place and positions adopted in measurements of BP and HR at rest). None of the measurements obtained was discarded. At each point, HR records in beats per minute (bpm) and $\mathrm{mmHg}$ for SBP and DBP were used to calculate the MBP by means of the ratio $\mathrm{MBP}=\mathrm{SBP}+(\mathrm{DBP} x$ 2) $/ 3$ and the double product (DP) using the equation DP = SBP $\mathrm{x}$ HR [33].

\section{Statistical analysis}

The descriptive statistics include calculations of the mean, standard deviation (SD), and the minimum and maximum of the dependent variables. The Shapiro-Wilk test was used to verify the normality of the dependent variables. A multivariate analysis of variance (MANOVA) was performed to check and 
compare the behaviour of SBP, DBP, MBP, HR, and DP after the training sessions. A one-way ANOVA (moments) was performed to compare the intra-group values between moments for repeated measures, followed by post hoc Bonferroni testing when needed. A two-way ANOVA $(2 \times 3)$ was used to assess differences between the methods and series regarding the performance of repetitions and training volume. The Friedman test was used to compare the PE between the protocols and series. The calculations were performed using SPSS software version 20.0. The critical level of significance for the tests was $5 \%(p<0.05)$.

\section{Results}

Table 1 shows the data on the body composition of participants. The results of the Shapiro-Wilk test for these variables exhibited a near normal distribution curve.

Table 1. Sample characteristics $(\mathrm{n}=15)$

\begin{tabular}{|c|c|c|c|c|c|c|c|c|}
\hline & $\begin{array}{c}\text { Age } \\
(\text { years })\end{array}$ & $\begin{array}{c}\text { Stature } \\
(\mathbf{m})\end{array}$ & $\begin{array}{c}\text { TBM } \\
(\mathbf{k g})\end{array}$ & $\begin{array}{c}\text { SMM } \\
(\mathbf{k g})\end{array}$ & $\begin{array}{c}\text { FFM } \\
(\mathbf{k g})\end{array}$ & $\begin{array}{c}\text { FM } \\
(\mathbf{k g})\end{array}$ & $\begin{array}{c}\text { \%F } \\
\left(\mathbf{k g} / \mathbf{m}^{2}\right)\end{array}$ \\
\hline Mean & 25.1 & 1.78 & 78.4 & 39.1 & 68.0 & 10.4 & 13.2 & 24.78 \\
\hline SD & 3.2 & 0.1 & 8.4 & 4.3 & 7.2 & 2.6 & 2.9 & 1.4 \\
\hline Minimum & 22 & 1.67 & 64.6 & 31.3 & 55.0 & 5.6 & 7.7 & 23.15 \\
\hline Maximum & 34 & 1.92 & 97.1 & 48.9 & 84.3 & 14.4 & 18.3 & 27.62 \\
\hline $\begin{array}{c}\text { SW } \\
(p-v a l u e)\end{array}$ & 0.016 & 0.713 & 0.866 & 0.845 & 0.857 & 0.751 & 0.869 & 0.001 \\
\hline
\end{tabular}

TBM = total body mass; SMM = skeletal muscle mass; FFM = fat-free mass; FM = fat mass; $\% \mathrm{~F}$ = fat percentage; $\mathrm{BMI}=$ body mass index; $\mathrm{SD}$ = standard deviation; $\mathrm{SW}$ (p-value $)=$ Shapiro-Wilk normality test.

Regarding the SBP, there were no differences between the training methods. No interactions were found between the protocols and measures (Tab. 2). However, significant intraprotocol differences were observed between the moments $(\mathrm{F}=$ 21.848; $\mathrm{p}=0.0001)$.

At the rest moment, the SBP in both the DeLorme and Oxford Protocols increased significantly, immediately after exertion. Its significant reduction in both methods was achieved from 40 minutes, extending until the last minute analysed.

Table 2. Mean (SD) of systolic blood pressure between protocols $(\mathrm{n}=15)$

\begin{tabular}{|c|c|c|c|c|c|c|c|c|}
\hline & Rest & $\begin{array}{c}\text { Post- } \\
\text { effort }\end{array}$ & $\begin{array}{c}10 \\
\text { min }\end{array}$ & $\begin{array}{c}\mathbf{2 0} \\
\mathbf{m i n}\end{array}$ & $\begin{array}{c}30 \\
\mathbf{m i n}\end{array}$ & $\begin{array}{c}40 \\
\mathbf{m i n}\end{array}$ & $\begin{array}{c}\mathbf{5 0} \\
\mathbf{m i n}\end{array}$ & $\begin{array}{c}60 \\
\mathbf{m i n}\end{array}$ \\
\hline DeLorme & $\begin{array}{c}120 \\
(3.9)\end{array}$ & $\begin{array}{c}140 \\
(10.6)^{*}\end{array}$ & $\begin{array}{c}124 \\
(7.4)\end{array}$ & $\begin{array}{c}120 \\
(6.2)\end{array}$ & $\begin{array}{c}117 \\
(5.3)\end{array}$ & $\begin{array}{c}115 \\
(5.5)^{*}\end{array}$ & $\begin{array}{c}114 \\
(4.7)^{*}\end{array}$ & $\begin{array}{c}113 \\
(4.7)^{*}\end{array}$ \\
\hline Oxford & $\begin{array}{c}120 \\
(4.1)\end{array}$ & $\begin{array}{c}144 \\
(11.3)^{*}\end{array}$ & $\begin{array}{c}126 \\
(6.4)\end{array}$ & $\begin{array}{c}121 \\
(4.8)\end{array}$ & $\begin{array}{c}117 \\
(5.9)\end{array}$ & $\begin{array}{c}114 \\
(4.5)^{*}\end{array}$ & $\begin{array}{c}113 \\
(3.8)^{*}\end{array}$ & $\begin{array}{c}112 \\
(3.7)^{*}\end{array}$ \\
\hline
\end{tabular}

* = significant difference with respect to the rest value.
Regarding DBP, there were no differences between the training methods. No interactions were found between the protocols and measures (Tab. 3). However, significant intra-protocol differences were observed between the moments $(\mathrm{F}=46.113$; $\mathrm{p}=$ 0.0001).

At the rest moment, the DBP in both the DeLorme and Oxford Protocols increased significantly immediately after exertion, but a significant reduction in both methods was only obtained after 60 minutes.

Table 3. Mean (SD) of diastolic blood pressure between protocols $(n=15)$

\begin{tabular}{|c|c|c|c|c|c|c|c|c|}
\hline & Rest & $\begin{array}{c}\text { Post- } \\
\text { effort }\end{array}$ & $\mathbf{1 0}$ min & $\mathbf{2 0} \mathbf{m i n}$ & $\mathbf{3 0} \mathbf{m i n}$ & $\mathbf{4 0} \mathbf{m i n}$ & $\mathbf{5 0} \mathbf{m i n}$ & $\mathbf{6 0} \mathbf{m i n}$ \\
\hline $\begin{array}{c}\text { De } \\
\text { Lorme }\end{array}$ & $\begin{array}{c}67 \\
(6.2)\end{array}$ & $\begin{array}{c}83 \\
(13.2)^{*}\end{array}$ & $\begin{array}{c}70 \\
(9.1)\end{array}$ & $\begin{array}{c}68 \\
(6.2)\end{array}$ & $\begin{array}{c}66 \\
(6.7)\end{array}$ & $\begin{array}{c}64 \\
(5.1)\end{array}$ & $\begin{array}{c}62 \\
(3.8)\end{array}$ & $\begin{array}{c}61 \\
(4.0)^{*}\end{array}$ \\
\hline Oxford & $\begin{array}{c}68 \\
(4.8)\end{array}$ & $\begin{array}{c}85 \\
(11.7)^{*}\end{array}$ & $\begin{array}{c}73 \\
(9.8)\end{array}$ & $\begin{array}{c}71 \\
(7.7)\end{array}$ & $\begin{array}{c}67 \\
(5.7)\end{array}$ & $\begin{array}{c}66 \\
(4.5)\end{array}$ & $\begin{array}{c}64 \\
(4.6)\end{array}$ & $\begin{array}{c}63 \\
(4.2)^{*}\end{array}$ \\
\hline
\end{tabular}

* = significant difference with respect to the rest value.

In relation to $\mathrm{MBP}$, differences were observed between the training methods $(\mathrm{F}=4.938 ; \mathrm{p}=0.043)$ (Tab. 4). In addition, interactions were found between the protocols and measures $(\mathrm{F}=8.504 ; \mathrm{p}=0.0001)$. However, significant intra-protocol differences were observed between the moments $(\mathrm{F}=64.074 ; \mathrm{p}=$ 0.0001).

At the rest moment, the MBP in both the DeLorme and Oxford Protocols increased significantly immediately after exertion, but it was higher in the Oxford Protocol. The significant reduction of MBP in both methods was achieved from 50 minutes through the last minute, but in the $10^{\text {th }}$ and $20^{\text {th }}$ minutes, the DeLorme Protocol MBP was significantly lower than the MBP of the Oxford Protocol.

Table 4. Mean (SD) of mean blood pressure between protocols $(n=15)$

\begin{tabular}{|c|c|c|c|c|c|c|c|c|}
\hline & Rest & $\begin{array}{c}\text { Post- } \\
\text { effort }\end{array}$ & $\mathbf{1 0} \mathbf{m i n}$ & $\mathbf{2 0} \mathbf{m i n}$ & $\mathbf{3 0} \mathbf{m i n}$ & $\mathbf{4 0} \mathbf{m i n}$ & $\mathbf{5 0} \mathbf{~ m i n}$ & $\mathbf{6 0} \mathbf{m i n}$ \\
\hline $\begin{array}{c}\text { De } \\
\text { Lorme }\end{array}$ & $\begin{array}{c}85.0 \\
(5.2)\end{array}$ & $\begin{array}{c}93.4 \\
(7.0)^{*}\end{array}$ & $\begin{array}{c}87.9 \\
(7.7)\end{array}$ & $\begin{array}{c}85.2 \\
(5.2)\end{array}$ & $\begin{array}{c}82.7 \\
(5.3)\end{array}$ & $\begin{array}{c}80.9 \\
(4.2)\end{array}$ & $\begin{array}{c}79.4 \\
(3.1)^{*}\end{array}$ & $\begin{array}{c}78.0 \\
(3.6)^{*}\end{array}$ \\
\hline Oxford & $\begin{array}{c}85.4 \\
(4.1)\end{array}$ & $\begin{array}{c}104.7 \\
(10.2)^{*} \dagger\end{array}$ & $\begin{array}{c}90.8 \\
(7.9) \dagger\end{array}$ & $\begin{array}{c}87.4 \\
(6.2) \dagger\end{array}$ & $\begin{array}{c}83.7 \\
(4.8)\end{array}$ & $\begin{array}{c}81.9 \\
(4.0)\end{array}$ & $\begin{array}{c}80.5 \\
(3.7)^{*}\end{array}$ & $\begin{array}{c}79.0 \\
(3.6)^{*}\end{array}$ \\
\hline
\end{tabular}

* = significant difference with respect to the rest value;

$\dagger=$ significant difference with respect to the DeLorme method.

Regarding HR, differences were observed between the training methods $(\mathrm{F}=5.064 ; \mathrm{p}=0.041)$ (Tab. 5). In addition, interactions were found between the protocols and measures $(\mathrm{F}=3.060 ; \mathrm{p}=0.006)$. However, significant intra-protocol differences were observed between the moments $(\mathrm{F}=237.415 ; \mathrm{p}=$ 0.0001).

At the rest moment, the HR in both the DeLorme and Oxford Protocols reduced significantly only after 60 minutes, remaining significantly raised until 40 minutes in the postexercise moment. The values of HR were significantly higher until 20 minutes in the Oxford Protocol of post-exercise than in the DeLorme Protocol. 
Table 5. Mean (SD) of heart rate (HR) between protocols $(\mathrm{n}=15)$

\begin{tabular}{|c|c|c|c|c|c|c|c|c|}
\hline & Rest & $\begin{array}{c}\text { Post- } \\
\text { effort }\end{array}$ & $10 \min$ & $20 \min$ & $30 \min$ & 40 min & 50 min & 60 min \\
\hline $\begin{array}{c}\text { De } \\
\text { Lorme }\end{array}$ & $\begin{array}{c}58 \\
(4.4)\end{array}$ & $\begin{array}{c}120 \\
(12.4)^{*}\end{array}$ & $\begin{array}{c}83 \\
(13.4)^{*}\end{array}$ & $\begin{array}{c}74 \\
(9.0)^{*}\end{array}$ & $\begin{array}{c}65 \\
(7.4)^{*}\end{array}$ & $\begin{array}{c}61 \\
(5.6)^{*}\end{array}$ & $\begin{array}{c}57 \\
(4.0)\end{array}$ & $\begin{array}{c}55 \\
(2.9)^{*}\end{array}$ \\
\hline Oxford & $\begin{array}{c}58 \\
(4.7)\end{array}$ & $\begin{array}{c}130 \\
(18.4)^{*} \dagger\end{array}$ & $\begin{array}{c}86 \\
(13.4)^{*} \dagger\end{array}$ & $\begin{array}{c}76 \\
(10.2)^{*} \dagger\end{array}$ & $\begin{array}{c}66 \\
(6.5)^{*}\end{array}$ & $\begin{array}{c}61 \\
(3.7)^{*}\end{array}$ & $\begin{array}{c}58 \\
(3.9)\end{array}$ & $\begin{array}{c}55 \\
(3.9)^{*}\end{array}$ \\
\hline
\end{tabular}

* $=$ significant difference with respect to the rest value; $\dagger=$ significant difference with respect to the DeLorme method.

As for the DP, differences were observed between the training methods $(F=6.158 ; p=0.026)$ (Tab. 6). In addition, interactions were found between the protocols and measures $(\mathrm{F}=$ 4.961; $\mathrm{p}=0.0001)$. However, significant intra-protocol differences were observed between the moments $(\mathrm{F}=237.601 ; \mathrm{p}=$ $0.0001)$.

At the rest moment, the DP in both the DeLorme and Oxford Protocols showed significant reduction only after 50 and 60 minutes, remaining significantly raised until 30 minutes of the post-exercise moment. The values of DP were significantly higher until 20 minutes in the Oxford Protocol of post-exercise than in the DeLorme Protocol.

Table 6. Mean (SD) of double product (DP) between protocols $(\mathrm{n}=15)$

\begin{tabular}{|c|c|c|c|c|c|c|c|c|}
\hline & Rest & $\begin{array}{l}\text { Post- } \\
\text { effort }\end{array}$ & $10 \mathrm{~min}$ & $20 \mathrm{~min}$ & $30 \mathrm{~min}$ & $40 \mathrm{~min}$ & $50 \mathrm{~min}$ & $60 \mathrm{~min}$ \\
\hline $\begin{array}{l}\text { De } \\
\text { Lorme }\end{array}$ & $\begin{array}{l}7013.2 \\
(596.1)\end{array}$ & $\begin{array}{c}16786.9 \\
(2069.2)^{*}\end{array}$ & $\begin{array}{c}10316.1 \\
(1963.5)^{*}\end{array}$ & $\begin{array}{c}8885.3 \\
(1215.6)^{*}\end{array}$ & $\begin{array}{l}7638.0 \\
(911.9)^{*}\end{array}$ & $\begin{array}{l}6959.4 \\
(746.0)\end{array}$ & $\begin{array}{l}6529.6 \\
(546.4)^{*}\end{array}$ & $\begin{array}{c}6227.3 \\
(430.1)^{*}\end{array}$ \\
\hline Oxford & $\begin{array}{l}6958.1 \\
(597.0)\end{array}$ & $\begin{array}{c}18747.3 \\
(3534.5)^{*} \dagger\end{array}$ & $\begin{array}{c}10819.7 \\
(1963.3)^{*}+\end{array}$ & $\begin{array}{c}9144.0 \\
(1273.1)^{*}+\end{array}$ & $\begin{array}{c}7726.2 \\
(968.2)^{*}\end{array}$ & $\begin{array}{l}6960.9 \\
(632.9)\end{array}$ & $\begin{array}{l}6509.7 \\
(602.1)^{*}\end{array}$ & $\begin{array}{l}6159.0 \\
(574.4)^{*}\end{array}$ \\
\hline
\end{tabular}

* $=$ significant difference with respect to the rest value; $\uparrow=$ significant difference with respect to the DeLorme Method.
In the repetitions of the SM, differences were observed between the training methods $(\mathrm{F}=35.374 ; \mathrm{p}=0.0001)$ (Tab. 7). In addition, no interactions were found between the protocols and measures; however, significant intra-protocol differences were observed between sets $(F=318.595 ; \mathrm{p}=0.0001)$. As for the performance in the repetitions in the LP, no differences were observed between the training methods $(F=24.274 ; \mathrm{p}=0.0001)$. Additionally, no interactions were found between the protocols and measures; however, significant intra-protocol differences between the series $(\mathrm{F}=107.671 ; \mathrm{p}=0.0001)$ were observed.

As for the volume of training in SM, no differences were observed between the training methods. On the other hand, interactions were found between the protocols and measures $(\mathrm{F}=$ 4.288; $\mathrm{p}=0.024)$. However, significant intra-protocol differences were observed between the series $(F=194.487$; $\mathrm{p}=0.0001)$. Regarding the LP, no differences were observed between the training methods. On the other hand, interactions were found between the protocols and measures $(\mathrm{F}=4.237 ; \mathrm{p}=0.025)$. Moreover, significant intra-protocol differences were observed between the series $(F=69.681 ; p=0.0001)$.

Regarding PE, there was a significant difference between the training methods $(\mathrm{p}=0.0001)$.

The data obtained in this research showed that muscular performance in SM and in LP in both methods, as measured by the volume of training and number of maximum repetitions, was reduced. Both Drop 2 and Drop 3 had lower incremental performance when compared to the numbers achieved in Drop 1. In Drop 1, the PE in SM in the Oxford Protocol was higher than in the DeLorme Protocol, and in Drop 3, the PE in SM was higher in the DeLorme Protocol than in the Oxford Protocol.

The maximum repetitions performed in the DeLorme Protocol in the 3 Drops performed in SM and LP were higher than in the Oxford Protocol. There was no difference in volume between the methods in drops performed in SM, but the DeLorme Protocol training volumes in Drops 2 and 3 executed on LP were higher than in the Oxford Protocol.

\section{Discussion}

The present study investigated the hypotensive effect induced by ST performed using the DeLorme and Oxford methods

Table 7. Mean (SD) of the performance of maximum repetitions, training volume, and perceived exertion (PE) $(\mathrm{n}=15)$

\begin{tabular}{|c|c|c|c|c|c|c|c|c|c|}
\hline & \multicolumn{3}{|c|}{ Drop 1} & \multicolumn{3}{|c|}{ Drop 2} & \multicolumn{3}{|c|}{ Drop 3} \\
\hline & $\begin{array}{c}\text { Repetition } \\
\text { maximum (RM) }\end{array}$ & $\begin{array}{c}\text { Training volume } \\
\text { (kg) }\end{array}$ & PE & $\begin{array}{c}\text { Repetition } \\
\text { maximum (RM) }\end{array}$ & $\begin{array}{c}\text { Training volume } \\
(\mathrm{kg})\end{array}$ & PE & $\begin{array}{c}\text { Repetition } \\
\text { maximum (RM) }\end{array}$ & $\begin{array}{l}\text { Training volume } \\
\text { (kg) }\end{array}$ & PE \\
\hline \multicolumn{10}{|c|}{ Smith Machine } \\
\hline DeLorme & $\begin{array}{c}35.6 \\
(3.1) \neq\end{array}$ & $\begin{array}{l}1852.90 \\
(355.9)\end{array}$ & $\begin{array}{c}8.2 \\
(0.4)\end{array}$ & $\begin{array}{c}27.6 \\
(2.9) \neq \S\end{array}$ & $1400.35(217.2) \S$ & $\begin{array}{c}8.9 \\
(0.7)\end{array}$ & $\begin{array}{c}22.3 \\
(2.5) \neq \S \beta\end{array}$ & $\begin{array}{c}1118.57 \\
(212.3) \S \beta\end{array}$ & $\begin{array}{c}9.9 \\
(0.4) ¥\end{array}$ \\
\hline Oxford & $\begin{array}{l}30.9 \\
(3.4)\end{array}$ & $\begin{array}{l}1912.42 \\
(334.9)\end{array}$ & $\begin{array}{c}8.4 \\
(0.5) \dagger\end{array}$ & $\begin{array}{c}24.3 \\
(5.5) \S\end{array}$ & $1482.33(416.0) \S$ & $\begin{array}{c}9.1 \\
(0.5)\end{array}$ & $\begin{array}{c}16.9 \\
(3.7) \S \beta\end{array}$ & $\begin{array}{c}1023.45 \\
(271.1) \S \beta\end{array}$ & $\begin{array}{c}9.6 \\
(0.5)\end{array}$ \\
\hline \multicolumn{10}{|c|}{ Leg Press $45^{\circ}$} \\
\hline DeLorme & $\begin{array}{c}24.7 \\
(4.4) ¥\end{array}$ & $3927.00(1209.4)$ & $\begin{array}{c}9.1 \\
(0.6)\end{array}$ & $\begin{array}{c}19.9 \\
(4.0) \neq \S\end{array}$ & $\begin{array}{c}3081.13(751.5) \\
\neq \S\end{array}$ & $\begin{array}{c}9.5 \\
(0.6)\end{array}$ & $\begin{array}{c}17.5 \\
(4.9) \neq \S \beta\end{array}$ & $\begin{array}{c}2471.93(686.5) \\
¥ \S \beta\end{array}$ & $\begin{array}{c}9.9 \\
(0.3)\end{array}$ \\
\hline Oxford & $\begin{array}{l}21.3 \\
(4.1)\end{array}$ & $3936.47(1054.9)$ & $\begin{array}{c}9.1 \\
(0.5)\end{array}$ & $\begin{array}{c}15.1 \\
(3.8) \S\end{array}$ & $2700.93(718.8) \S$ & $\begin{array}{c}9.3 \\
(0.6)\end{array}$ & $\begin{array}{c}11.5 \\
(3.2) \S \beta\end{array}$ & $\begin{array}{c}2008.80 \\
(606.0) \S \beta\end{array}$ & $\begin{array}{c}9.9 \\
(0.4)\end{array}$ \\
\hline
\end{tabular}

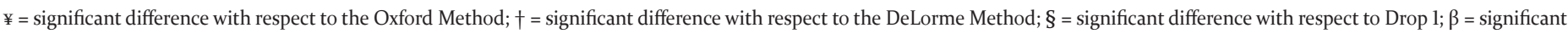
difference with respect to Drop 2. 
on BP in normotensive trained individuals. The results showed that the PEH was not influenced by the different ST methods. This statement is supported by the significant reduction in pressure values observed after the completion of the training sessions in both methods at rest compared to hemodynamic values at rest.

It was evident that the DeLorme and Oxford Protocols increased hemodynamic responses immediately post-exercise, compared to the values obtained at rest. Such a result can be explained by the variables that contribute to the elevation of BP manifested during high intensity physical activity, such as the chemoreceptor activated by peripheral fatigue [34].

However, the results of this intervention in both methods showed significant reductions in SBP compared to rest from 40 minutes, lasting through the $60^{\text {th }}$ minute, with significant reductions in DBP compared to rest at the last minute. In studies with ST, Brum et al. [35] found that in normotensive individuals, $\mathrm{PEH}$ is due to reduced cardiac output by reduction of systolic volume, and this loss is not offset by increased reduction in peripheral vascular resistance (PVR). This mechanism appears to be the same in exercises of high and low intensity but, when considering a longer period after high intensity exercise, the PVR in early recovery partially compensates for the reduction in cardiac output, preventing a reduced DBP, but not a reduced $\mathrm{SBP}$

Polito et al. [36] evaluated the influence of different intensity protocols matched by volume (product of sets, repetitions, and load) in 16 volunteers who underwent the following two protocols in circuit: a) three series of 6RM with a stipulated recovery interval of two minutes (SEQ6); b) the same procedure, but with three sets of 12 reps with a load corresponding to $50 \%$ of 6RM (SEQ12). The hypotensive effects obtained with respect to post-effort SBP, as those found in the present research, were similar in both protocols. However, when it comes to DBP, after effort, the SEQ12 afforded a significant reduction in less than 20 minutes, while SEQ6 did not result in significant changes.

In the present study, the significant reduction in DBP in both methods was only obtained after 60 minutes. The literature suggests that there are several factors that can influence the responses of DBP post-exercise, such as muscle action type, session length, time under tension, and intensity [37]. Bentes et al. [17] adopted different training methods, intensities, and orders of exercises for the upper limbs to carry out a study on the behaviour of BP after ST in women during their menstrual period. The authors found higher PEH for SBP and DBP, which remained 15 minutes after the training session when the subjects exercised with greater intensity ( $80 \%$ of $1 \mathrm{RM})$, independent of the exercise order.

In both the DeLorme and Oxford Protocols, there were significant reductions in MBP in relation to rest from 50 minutes until the last minute. In a pilot study by Cunha et al. [38], the results showed that after eight weeks of ST with moderate intensity, there were significant reductions in DBP and MBP at rest. Similarly, the same ST period with low intensity induced significant reduction in MBP at rest in controlled hypertension in elderly women.

The DP, which is considered the best non-invasive indicator to evaluate the myocardial oxygen consumption $\left(\mathrm{MVO}_{2}\right)$ during rest or effort, is very effective as an indicator of cardiac overload in ST [39]. In this study, both in the DeLorme and Oxford Protocols, a significant reduction was reached at 50 and 60 minutes, and DP remained significantly increased post-effort until the $30^{\text {th }}$ minute. However, low cardiovascular risk is evidenced in the conducts adopted in the ST sessions of this study, since both protocols had mean values below the cut-off point suggested for angina pectoris (30.000 $\mathrm{mmHg} . \mathrm{bpm})$ [40]

ST, among others, is responsible for stimulating the production of several regulatory substances in the organism. Nitric oxide is one of them. It is secreted from the endothelium and is responsible for vasodilation, which facilitates blood circulation and metabolic functions necessary for recovery in exercise [41]. With increasing vasodilation post-training, the levels of BP are reduced for up to 24 hours in hypertensive subjects. Therefore, regular exposure to $\mathrm{PEH}$ may reduce $\mathrm{BP}$ levels at rest, leading to a decrease in PVR, that is, continuous dilation of blood vessels, thus facilitating blood circulation [42].

The occurrence of PEH can be justified by the vasodilator effect of prostaglandins and nitric oxide released during exercise, as well as the inhibition of sympathetic activity (noradrenaline), a reduction of angiotensin II, circulating adenosine, and endothelin and its receptors in the central nervous system. This generally favours PVR and increases baroreflex sensitivity [43].

In the study conducted by Kelley and Kelley [44], there was a reduction of approximately $3 \mathrm{mmHg}$ in the group participating in the ST programme. These decreases were equivalent to reductions of 2 and 4\%, respectively, for SBP and DBP. From the clinical point of view, these modest changes in hypertensive populations are sufficient to provide decreases from 5 to $9 \%$ in the risk of coronary heart disease, 8 to $14 \%$ in that of stroke, and $4 \%$ in the risk of mortality.

Kenney and Seals [45] reported that the responses of the $\mathrm{BP}$ can differ between normotensive and hypertensive people, since the PEH may be associated with the health status of individuals. It was evident that the pressure reduction is of greater magnitude in hypertensive patients. In them, the fall in SBP and DBP after exercise varies from $18 \mathrm{mmHg}$ to $20 \mathrm{mmHg}$ and $7 \mathrm{mmHg}$ to $9 \mathrm{mmHg}$, respectively. In contrast, these variables present a less relevant magnitude in normotensive persons, being $8 \mathrm{mmHg}$ to $10 \mathrm{mmHg}$ in SBP and $3 \mathrm{mmHg}$ to $5 \mathrm{mmHg}$ in DBP, like those observed in this study.

O'Connor et al. [46] analysed the BP responses in 14 women (age: $22.6 \pm 3.9$ years; height: $164.4 \pm 8.7 \mathrm{~cm}$; BMI: $61.3 \pm 9.0 \mathrm{~kg}$ ) between 30 minutes and two hours after an ST session of three series with varying intensity for each of them $(40 \%, 60 \%$, and $80 \%$ of 10RM) in the following exercises: leg extension, leg curl, pull down, chest press, shoulder press, and abdominal crunch. In contrast to the results obtained in the present study, they found no significant reductions in DBP, although SBP was significantly elevated.

Some contradictory results were obtained, probably due to not maintaining the same parameters between ST prescription methods. According to Lizardo and Simões [47], there is still a lack of information about the intensity, muscle groups involved, body segments, magnitude, and duration of the reduction in post-exercise BP, indicating that there is a need to define the characteristics of that type of exercise, the method used, and the circumstances in which it is possible to induce PEH.

Some limitations of this study may have influenced its results: the sample was composed of normotensive subjects, who get less significant hypotensive results than is the case with interventions with hypertensive subjects. Another limiting factor was the measurement of BP with a digital pressure device. Intra-arterial catheterisation, despite being considered the gold standard in the structural conditions of this research, proved not to be feasible owing to its invasive procedure and its considerable risks for the health of the participants. 


\section{Conclusions}

With respect to $\mathrm{BP}$ values observed at rest, the DeLorme and Oxford methods used with the volume and intensity characteristics prescribed in this study, were able to induce a hypotensive effect of SBP from 40 minutes remaining through the $60^{\text {th }}$ minute, of DBP at the last minute, and of MBP at 50 and 60 minutes. When evaluated using DP, the training sessions indicated a low risk of cardiac overloads throughout the ST. It is recommended that future studies increase the sample size and intervention time to make it possible to investigate acute and sub-acute reductions in BP post-training, with exercises for the same muscle groups or others, as well as the chronic decrease of BP through continued ST.

\section{Literature}

1. Ram C.V., Giles T.D. (2010). The evolving definition of systemic arterial hypertension. Current Atherosclerosis Reports 12, 155-158. DOI: 10.1007/s11883-010-0107-6.

2. Williams B. (2010). The year in hypertension. Journal of the American College of Cardiology 55, 66-73. DOI: 10.1016/j. jacc.2008.03.010.

3. Shrivastava S.R., Shrivastava P.S., Ramasamy J. (2014). The determinants and scope of public health interventions to tackle the global problem of hypertension. International Journal of Preventive Medicine 5, 807-812.

4. Donnelly J.E., Blair S.N., Jakicic J.M., Manore M.M., Rankin J.W., Smith B.K. et al. (2009). American College of Sports Medicine position stand. Appropriate intervention strategies for weight loss and prevention of weight regain for adults. Medicine \& Science in Sports E Exercise 41, 459471. DOI: 10.1249/MSS.0b013e3181949333.

5. Bernatova I. (2014). Endothelial dysfunction in experimental models of arterial hypertension: Cause or consequence? BioMed Research International 2014, 598271. DOI: $10.1155 / 2014 / 598271$.

6. Braith R.W., Stewart K.J. (2006). Resistance exercise training: Its role in the prevention of cardiovascular disease. Circulation 113, 2642-2650. DOI: 10.1161/CIRCULATIONAHA.105.584060.

7. Harris M.B., Slack K.N., Prestosa D.T., Hryvniak D.J. (2010). Resistance training improves femoral artery endothelial dysfunction in aged rats. European Journal of Applied Physiology 108, 533-540. DOI: 10.1007/s00421-009-1250-z.

8. Pricher M.P., Holowatz L.A., Williams J.T., Lockwood J.M., Halliwill J.R. (2004). Regional hemodynamics during postexercise hypotension I. Splanchnic and renal circulations. Journal of Applied Physiology 97, 2065-2070. DOI: 10.1152/ japplphysiol.00465.2004.

9. Brownley K.Y.A., Hinderliter A.L., West S.G., Girdler S.S., Sherwood A., Light K.C. (2003). Sympathoadrenergic mechanisms in reduced hemodynamic stress responses after exercise. Medicine $\mathcal{E}$ Science in Sports E Exercise 35, 978986. DOI: 10.1249/01.MSS.0000069335.12756.1B.

10. MacDonald J.R. (2002). Potential causes, mechanisms and implications of post exercise hypotension. Journal of $\mathrm{Hu}$ man Hypertension 16, 225-236. DOI: 10.1038/sj.jhh.1001377.

11. Simões G.C., Moreira S.R., Kushnick M.R., Simões H.G., Campbell C.S. (2010). Postresistance exercise blood pressure reduction is influenced by exercise intensity in type- 2 diabetic and nondiabetic individuals. Journal of Strength and Conditioning Research 24, 1277-1284. DOI: 10.1519/ JSC.0b013e3181d67488.
12. Bentes C.M., Simão R., Bunker T., Rhea M.R., Miranda H., Gomes T.M. et al. (2012). Acute effects of dropsets among different resistance training methods in upper body performance. Journal of Human Kinetics 34, 105-111. DOI: 10.2478/v10078-012-0069-6.

13. Nobrega A.C. (2005). The subacute effects of exercise: Concept, characteristics, and clinical implications. Exercise and Sport Sciences Reviews 33, 84-87.

14. Simão R., Salles B.F., Figueiredo T., Dias I., Willardson J.M. (2012). Exercise order in resistance training. Sports Medicine 42, 251-265. DOI: 10.2165/11597240-00000000000000.

15. Rezk C.C., Marrache R.C., Tinucci T., Mion D. Jr, Forjaz C.L. (2006). Post-resistance exercise hypotension, hemodynamics, and heart rate variability: Influence of exercise intensity. European Journal of Applied Physiology 98, 105-112.

16. Prista A., Macucule C.F., Queiroz A.C., Silva N.D. Jr, Cardoso C.G. Jr, Tinucci T. et al. (2013). A bout of resistance exercise following the 2007 AHA guidelines decreases asleep blood pressure in Mozambican men. Journal of Strength and Conditioning Research 27, 786-792. DOI: 10.1519/ JSC.0b013e31825d9783.

17. Bentes C.M., Costa P.B., Neto G.R., Silva G.V.C., Salles B.F., Miranda H.L. et al. (2015). Hypotensive effects and performance responses between different resistance training intensities and exercise orders in apparently health women. Clinical Physiology and Functional Imaging 35, 185-190. DOI: $10.1111 /$ cpf.12144.

18. Cornelissen V.A., Fagard R.H., Coeckelberghs E., Vanhees L. (2011). Impact of resistance training on blood pressure and other cardiovascular risk factors: A meta-analysis of randomized, controlled trials. Hypertension 58, 950-958. DOI: 10.1161/HYPERTENSIONAHA.111.177071.

19. Duncan M.J., Birch S.L., Oxford S.W. (2014). The effect of exercise intensity on postresistance exercise hypotension in trained men. Journal of Strength and Conditioning Research 28(6), 1706-1713. DOI: 10.1519/JSC.0000000000000322.

20. American College of Sports Medicine. (2014). ACSM's guidelines for exercise testing and prescription (9th ed.). Philadelphia: Wolters Kluwer; Lippincott Williams \& Wilkins.

21. Karelis A.D., Chamberland G., Aubertin-Leheudre M., Duval C. Ecological mobility in Aging and Parkinson (EMAP) group. (2013). Validation of a portable bioelectrical impedance analyzer for the assessment of body composition. Applied Physiology, Nutrition, and Metabolism 38, 2732. DOI: 10.1139/apnm-2012-0129.

22. Marfell-Jones M., Stewart A., Carter L. (2006). International standards for anthropometric assessment. Potchefstroom, South Africa: ISAK.

23. Guedes D.P. (2013). Clinical procedures used for analysis of the body composition. Brazilian Journal of Kinanthropometry and Human Performance 15, 113-129.

24. Baechle T.R., Earle R.W. (2008). Essentials of strength training and conditioning ( $3^{\text {rd }}$ ed.). Champaign, IL: Human Kinetics.

25. Monteiro W., Simão R., Farinatti P. (2005). Manipulation of exercise order and its influence on the number of repetitions and effort subjective perception in trained women. Brazilian Journal of Sports Medicine 11, 143e-146e.

26. Simão R., Fleck S.J., Polito M., Monteiro W., Farinatti P. (2005). Effects of resistance training intensity, volume, and session format on the post exercise hypotensive response. Journal of Strength and Conditioning Research 19, 853-858. 
27. Simão R., Monteiro W., Jacometo A., Tesseroli C., Teixeira G. (2006). The influence of three different rest intervals between sets in loads to 10 repetitions maximum. Revista Brasileira de Ciência e Movimento 14, 37-44.

28. Lemos A., Simão R., Monteiro W., Polito M., Novaes J. (2008). Strength performance in older women after two intensities of aerobic exercise. Brazilian Journal of Sports Medicine 14, 28-32.

29. Cossenza C.E., Lima V.P. (2013). Resistance training: The practice of training methods ( $2^{\text {nd }}$ ed.). Rio de Janeiro: Sprint. [in Portuguese]

30. Lemos A., Simão R., Miranda F., Novaes J. (2007). Acute influence of a mini-trampoline class on squat. Fitness $\mathcal{E}$ Performance Journal 6, 76-81.

31. Naclerio F., Rodríguez-Romo G., Barriopedro-Moro M.I., Jiménez A., Alvar B.A., Triplett N.T. (2011). Control of resistance training intensity by the OMNI perceived exertion scale. Journal of Strength and Conditioning Research 25, 1879-1888. DOI: 10.1519/JSC.0b013e318le50le9.

32. Cuckson A.C., Reinders A., Shabeeh H., Shennan A.H., British Hypertension Society. (2002). Validation of the Microlife BP 3BTO-A oscillometric blood pressure monitoring device according to a modified British Hypertension Society protocol. Blood Pressure Monitoring 7, 319-324. DOI: 10.1097/01.mbp.0000047142.34024.dd.

33. Fox S.I. (2011). Human physiology (12 th ed.). New York: McGraw-Hill Companies.

34. Carrington C.A., White M.J. (2001). Exercise-induced muscle chemoreflex modulation of spontaneous baroreflex sensitivity in man. Journal of Physiology 536, 957-962.

35. Brum P.C., Forjaz C.L.M., Tinucci T., Negrão C.E. (2004). Acute and chronic adaptations of physical exercise in the cardiovascular system. Revista Paulista de Educação Física 18, 21-31. [in Portuguese]

36. Polito M.D., Simão R., Senna G.W., Farinatti P.T.V. (2003). Hypotensive effects of resistance exercises performed at different intensities and same work volumes. Brazilian Journal of Sports Medicine 9, 74-77.

37. Janning P.R., Cardoso A.C., Fleischmann E., Coelho C.W., Carvalho T. (2009). Influence of resistance exercises order performance on post-exercise hypotension in hypertensive elderly. Brazilian Journal of Sports Medicine 15, 338-341.

38. Cunha E.S., Nogueira P.A.M.S., Costa E.C., Silva E.P., Ferreira G.M.H. (2012). Resistance training intensities and blood pressure of hypertensive older women - a pilot study. Brazilian Journal of Sports Medicine 18, 373-376.

39. Polito M.D., Farinatti P.T.V. (2003). Heart-rate, blood pressure, and rate pressure product during resistive exercises: A review of the literature. Revista Portuguesa de Ciências do Desporto 3, 79-91. [in Portuguese]

40. Leite T.C., Farinatti P.T.V. (2003). Heart rate, systolic blood pressure and rate pressure product in different resistive exercises for similar muscle groups. Brazilian Journal of Exercise Physiology and Prescription 2, 29-49. [in Portuguese]

41. Brown M.D., Srinivasan M., Hogikyan R.V., Dengel D.R., Glickman S.G., Galecki A. et al. (2000). Nitric oxide biomarkers increase during exercise-induced vasodilation in the forearm. International Journal of Sports Medicine 21, 83-89.

42. Halliwill J.R. (2001). Mechanisms and clinical implications of post-exercise hypotension in humans. Exercise and Sport Sciences Reviews 29, 65-70.

43. Casonatto J., Doederlein M. (2009). Post-exercise hypotension: A systematic review. Brazilian Journal of Sports Medicine 15,151-157.

44. Kelley G.A., Kelley K.S. (2000). Progressive resistance exercise and resting blood pressure: A meta-analysis of randomized controlled trials. Hypertension 35, 838-843.

45. Kenney M.J., Seals D.R. (1993). Postexercise hypotension. Key features, mechanisms, and clinical significance. Hypertension 22, 653-664.

46. O'Connor P.J., Bryant C.X., Veltri J.P., Gebhardt S.M. (1993). State anxiety and ambulatory blood pressure following resistance exercise in females. Medicine $\mathcal{E}$ Science in Sports $\mathcal{E}$ Exercise 25, 516-521.

47. Lizardo J.H.F., Simões H.G. (2005). Effects of different resistance exercise sessions on post-exercise hypotension. Brazilian Journal of Physical Therapy 9, 289-295. [in Portuguese].

Submitted: October 24, 2017

Accepted: November 20, 2017 